\title{
Making contributions beyond theory-based studies: From the APJM editorial team
}

\section{APJM Editorial Team ${ }^{1}$}

Published online: 5 February 2020

(C) Springer Science+Business Media, LLC, part of Springer Nature 2020

The new editorial team of Asia Pacific Journal of Management (APJM) has now assumed its duties for just over a full year. First of all, we would like to express our sincere gratitude to those who have offered their services to assist in the smooth running of APJM. Second, the editorial team has discussed an important issue that we would like to communicate with potential authors. This issue is about the judgment of the contributions that a manuscript can make. Some authors and helpful reviewers have asked for clearer instructions on this issue of an article's contributions. While difficult, we believe it is necessary for us to try to express our views on this.

$A P J M$ is an academic journal. We look for rigorous scientific studies mainly in the areas of entrepreneurship, human resource management, international business, organizational behavior, and strategic management, all with an Asia relevance. It is inevitable that manuscripts need to use the state-of-the-art theories and methodologies so as to be able to contribute new or improved knowledge to the areas on which APJM focuses. Authors a are thus strongly recommended to review recent papers published by APJM and other relevant journals to see if their studies are following the state-ofthe-art theories and methodologies. It is also important to note that the Asia Pacific region represents a unique context for reconceptualization of the existing phenomena or exploration of new concepts. Consequently, novel contributions will use the Asia Pacific region as a fertile ground for context-based theory building (please see Barkema, Chen, George, Luo, \& Tsui, 2015 in this regard).

As for methodologies, it is relatively easy to judge the appropriateness in terms of how they fulfil the state-of-the-art requirement. For example, we have received some manuscripts, mostly in the areas of organizational behavior and human resource management, which still use cross-sectional data to examine potential mediation effects. This is certainly unacceptable because the chance of drawing incorrect conclusions is high (Law, Wong, Yan, \& Huang, 2016). In the area of strategic management, the issue of endogeneity has become an increasingly important concern and it is quite

APJM Editorial Team wongcs@cuhk.edu.hk

1 The Chinese University of Hong Kong, Shatin, NT, Hong Kong, SAR, People's Republic of China 
unacceptable for scientific studies that ignore this key issue (Semadeni, Withers, \& Certo, 2014).

\section{Overinterpretation of theory-based studies}

The more difficult judgement is about theoretical contributions because there is little consensus and concrete acceptable standards that we can use to make the judgment. We notice that some potential authors have taken a very narrow interpretation about theoretical contributions in that their studies must be theory-based. This means that they have to adopt a theory and deduce some hypotheses based on that theory. There is nothing wrong with theory-based studies. However, what we notice is that their studies are in fact not theory-based and the authors simply try to frame their paper to "pretend" that they are theory-based.

Theory-based studies certainly will contribute to the literature, but not all rigorous studies that can contribute to new knowledge need to be theory-based. There are other forms of scientific studies that can advance our knowledge such as phenomenological studies (Ahlstrom, 2015), which are discussed later. Furthermore, to our understanding, a truly theory-based study should use a theory to explain a phenomenon under investigation. All the variables and constructs must be based on the theory (or theories), and their relationships are derived from the assumptions and arguments of the applied theory. Unfortunately, we find a large number of submissions that simply borrow a general concept of a theory and then claim that their study is theory-based. For example, a number of studies claim that they apply Social Exchange Theory (Blau, 1964), but they only use the argument that employees will have some positive (or negative) attitudes and behaviors when they receive positive (or negative) treatment from their employers. In fact, this is the norm of reciprocity (Cialdini, 2006; Gouldner, 1960), not Social Exchange Theory. The key contributions of Social Exchange Theory should be the distinction between social (or relational) and economic exchanges instead of the norm of reciprocity. Another example is the application of the Conservation of Resources Theory (Hobfoll, 1988). The original idea of this theory is mostly about how people cope with stress by protecting the loss of resources or replacing the loss. The resources should be relevant to the particular coping mechanism. Unfortunately, we receive quite a few manuscript submissions simply label the variables under their investigation as a resource and argue almost all type of work attitudes and behaviors as attempts to protect the resource.

\section{Examples of misusing a theory: The case of signal theory}

Another example is the misuse or improper use of Signal or Signaling Theory. Our colleague, Professor Maoliang Bu has a more detail explanation in the following four paragraphs.

Signal or signaling theory is one of most popular theories applied by management researchers, ranging from a variety of fields including human resource management, entrepreneurship, strategy and so on (Bergh, Connelly, Ketchen Jr, \& Shannon, 2014; Boyd, Takacs, Hitt, Bergh, \& Ketchen, 2012). This theory originates from the work of 
Nobel Laureates George Akerlof (1970) and Michael Spence (1973) and has gained a high degree of visibility across a number of disciplines. Besides the visibility of the Nobel Prize, another critical reason for its popularity is perhaps its seemingly-easy function of application and interpretation. A signal, by its literal meaning, can be applied to nearly all kinds of actions of firms, since every particular action can be viewed as a signal of the focal firm to certain extent. Given the easier access to big data, such interpreting of firms' actions as signals is becoming more doable for management researchers.

However, the danger of misusing the signal theory will arise if the author lacks a thorough understanding of its substantive meaning and carelessly uses it symbolically. With the favor of using signal theory, the boundaries have been blurred in the management literature, leading to a lot of inconsistent terminology, which requires necessary clarification (Connelly, Certo, Ireland, \& Reutzel, 2011). While the separating equilibrium concept is essentially a predictive mechanism associated with signaling theory, Bergh et al. (2014) find that separating equilibrium has been paid little attention in their identified strategic management studies from 1980 to 2013. In fact, these studies used a variety of "signals" in different topics, such as top management team characteristics (Sauer, Thomas-Hunt, \& Morris, 2010), board ties (Reutzel \& Belsito, 2012), pricing of an initial public offering (Cohen \& Dean, 2005; Ndofor \& Levitas, 2004), and strategic alliances (Madhavan \& Prescott, 1995). In the next two paragraphs, we will briefly describe the key assumptions of signal theory without the use of mathematical language, and show how the theory is used improperly based on our description.

The origin of signal theory should at least include the following key assumptions (Wang, 2018). First, it starts with asymmetric information. Second, you need to simply consider two types of signalers: high quality vis-a-vis low quality. All signal theory users should be aware that not only the high quality type can send signals, but the low quality one can also send signals. In the original case of signal theory which drew on job markets, education is taken as a signal sent by job seekers (Spence, 1973). Low quality job seekers certainly can also choose to receive education. However, the cost is higher for them than the high quality job seekers. Third, the above type of difference leads to the cost difference of sending signals. In the job market case, low quality job seekers may also want to send signals. However, the low quality nature will constrain them to send signals (In other words, it can also be understood that not sending signals could be their optimal choice). With the above key assumptions, signal theory finally comes with the separating equilibrium. One extension of signal theory is contract theory, particularly the incomplete contracting part that economists often use and which for management researchers there are ample future research opportunities (for example, Yu, Lee, \& Han, 2015).

Deviating from the origin of signal theory, numerous examples have violated the assumptions. To sum up the violations, we would like to follow the key signal theory constructs provided by Connelly et al. (2011), which generally involves signal sender, signals, receivers, feedback and a signaling environment. We believe these key constructs jointly provide a sufficient setting for the correct application of signal theory. Management researchers are encouraged to use them to test whether a study has recognized the full set of assumptions. Failure to consider any of the key constructs can lead to the problematic misuse of signal theory. It is not our aim to list all the types 
of misuse in this paper. However, one can learn from the following example. In the intersectional field of international business and corporate social responsibility (CSR), researchers have attempted to integrate signal theory and argued to view CSR as a signal. We would like to remind readers that one must differentiate between the high quality signalers and the low quality ones, in addition to considering signaling cost differences. If not, the application of signal theory can be superficial or even incorrect.

\section{Beyond theory-based studies: Construct- and phenomenon-based studies}

We believe that theoretical contributions by a single study does not necessarily mean that the study has to be truly theory-based. Theoretical contributions can also be made by a single study in other ways. While it is certainly not exhaustive, our former colleague, Professor Daphne Yiu (now Associate Editor with the Academy of Management Journal), has recommended at least two other alternatives. The first one is a construct-based study. For this type of study, the focus is on a main construct and its relationship with other relevant variables in a particular domain. An example is some of the early investigations of the emotional intelligence construct (e.g., Law, Wong, \& Song, 2004; Wong \& Law, 2002). It seems too much to ask a single study to develop and validate a relatively new construct to be theory-based. Instead, the authors use the general human resource management framework to validate the construct. To develop a theory of emotional intelligence, much more than a single study is required (e.g., Law, Wong, Huang, \& Li, 2008). In our opinion, there are at least three important criteria to judge whether a construct based study can make a theoretical contribution, including (1) the construct should be distinct from other (seemingly similar) extant constructs (Christensen \& Carlile, 2009), (2) the construct can be put in a nomological network with important incremental validity on relevant variables in the particular academic field, and (3) in the long run a theory may be developed around this important construct (Huang, Ahlstrom, Lee, Chen, \& Hsieh, 2016).

The second alternative is phenomenon-based studies. That is, we observe a relevant phenomenon but extant theories do not seem to be able to fully explain it. For example, Wong and Law (1999) developed a model through qualitative interviews concerning how multinational corporations could replace their expatriates by local employees in China because the literature at the time was concerned mainly about expatriate management instead of the localization issue. This model was later tested and refined through large scale empirical studies (Law, Song, Wong, \& Chen, 2009; Law, Wong, \& Wang, 2004). As management theories are mostly originated from observations of phenomena of Western countries, it is possible that many phenomena in Asian countries may not be fully explained by existing theories. Through observing and conceptualizing some unique phenomena in Asia, we may develop new theories or enrich our existing theories (Ahlstrom, Chen, \& Yeh, 2010). In our opinion, there are at least three criteria to evaluate the theoretical contributions of phenomenon based studies for APJM, including (1) authors have to show that the phenomenon is really unique in the Asia context, (2) existing theories are either not applicable or need important modifications in order to explain the phenomenon, and (3) although we should not expect one single 
study to result in a well-established model or theory in explaining the unique phenomenon, in the long run this may be the result after a series of studies.

Is the classification of theory-, construct-, and phenomenon-based studies comprehensive? Certainly not. These are simply some common examples of scientific studies that can make meaningful contributions to the literature. There may be some other forms of rigorous scientific investigation that can make important contributions to new knowledge. The point we want to make here is that we should not be too narrow in judging the theoretical contributions that a single study can make, especially not to believe that only theory based studies are the correct form of rigorous scientific studies. If the studies are not truly theory-based, authors do not need to pretend that they are.

\section{Conclusion: We are looking for rigor and novelty}

Instead of narrowly defining their studies as theory-based, authors should ask themselves whether they can convince other colleagues that their studies: (1) are scientifically rigorous enough (i.e., rigor with respect to the state-of-the-art theories and methodologies); and (2) can advance our knowledge in the relevant field (i.e., novelty with respect to adding new understanding to the literature). If the answers are yes, then there is no need to frame their studies as if they are theory-based.

We understand that this issue will always be debatable and it is difficult to have some concrete standards to make this judgment. However, we hope that our discussion here can be a step towards a better understanding among the editorial team, reviewers, and potential authors of APJM. In short, we welcome any form of rigorous scientific studies that provide us with new knowledge in the academic areas on which APJM focus.

\section{References}

Ahlstrom, D. 2015. From the Editors: Publishing in the Journal of World Business. Journal of World Business, 50(2): 251-255.

Ahlstrom, D., Chen, S. J., \& Yeh, K. S. 2010. Managing in ethnic Chinese communities: Culture, institutions, and context. Asia Pacific Journal of Management, 27(3): 341-354.

Akerlof, G. A. 1970. Quality uncertainty and the market mechanism. The Quarterly Journal of Economics, 84(3): 488-500.

Barkema, H. G., Chen, X. P., George, G., Luo, Y., \& Tsui, A. S. 2015. West meets east: New concepts and theories. Academy of Management Journal, 58(2): 460-479.

Bergh, D. D., Connelly, B. L., Ketchen Jr., D. J., \& Shannon, L. M. 2014. Signaling theory and equilibrium in strategic management research: An assessment and a research agenda. Journal of Management Studies, 51(8): 1334-1360.

Blau, P. 1964. Exchange and power in social life. New York:Wiley.

Boyd, B. K., Takacs, H. K., Hitt, M. A., Bergh, D. D., \& Ketchen, D. J. 2012. Contingency hypotheses in strategic management research: Use, disuse, or misuse? Journal of Management, 38(1): 278-313.

Christensen, C. M., \& Carlile, P. R. 2009. Course research: Using the case method to build and teach management theory. Academy of Management Learning \& Education, 8(2): 240-251.

Cialdini, R. B. 2006. Influence: The psychology of persuasion. New York:Harper business.

Cohen, B. D., \& Dean, T. J. 2005. Information asymmetry and investor valuation of IPOs top management team legitimacy as a capital market signal. Strategic Management Journal, 26: 683-689.

Connelly, B. L., Certo, S. T., Ireland, R. D., \& Reutzel, C. R. 2011. Signaling theory: A review and assessment. Journal of Management, 37(1): 39-67. 
Gouldner, A. W. 1960. The norm of reciprocity: A preliminary statement. American Sociological Review, 25(2): 161-178.

Hobfoll, S. E. 1988. Conservation of resources: A new attempt at conceptualizing stress. American Pscyholgoist, 44(3): 513-524.

Huang, L. C., Ahlstrom, D., Lee, A. Y. P., Chen, S. Y., \& Hsieh, M. J. 2016. High performance work systems, employee well-being, and job involvement: An empirical study. Personnel Review, 45(2): 296-314.

Law, K. S., Song, L. J., Wong, C. S., \& Chen, C. 2009. The antecedents and consequences of successful localization. Journal of International Business Studies, 40: 1359-1373.

Law, K. S., Wong, C. S., Huang, G. H., \& Li, X. 2008. The effects of emotional intelligence on job performance and life satisfaction for the research and development scientists in China. Asia Pacific Journal of Management, 25(1): 51-69.

Law, K. S., Wong, C. S., \& Song, L. J. 2004. The construct validity of emotional intelligence and its potential utility for management studies. Journal of Applied Psychology, 89(3): 483-496.

Law, K. S., Wong, C. S., \& Wang, K. D. 2004. An empirical test of the model on managing the localization of human resources in the People's republic of China. International Journal of Human Resource Management, 15(5): 635-648.

Law, K. S., Wong, C. S., Yan, M., \& Huang, G. 2016. Asian researchers should be more critical: The example of testing mediators using time-lagged data. Asia Pacific Journal of Management, 33(2): 319-341.

Madhavan, R., \& Prescott, J. E. 1995. Market value impact of joint ventures: The effect of industry information-processing load. Academy of Management Journal, 38: 900-915.

Ndofor, H. A., \& Levitas, E. 2004. Signaling the strategic value of knowledge. Journal of Management, 30: 685-702.

Reutzel, C. R., \& Belsito, C. A. 2012. Examining the relative influence of upper echelons ties on IPO underpricing. International Entrepreneurship and Management Journal, 8: 1-14.

Sauer, S. J., Thomas-Hunt, M. C., \& Morris, P. A. 2010. Too good to be true? The unintended signaling effects of educational prestige on external expectations of team performance. Organization Science, 21: 11081120 .

Semadeni, M., Withers, M. C., \& Certo, S. T. 2014. The perils of endogeneity and instrumental variables in strategy research: Understanding through simulations. Strategic Management Journal, 35(7): 1070-1079.

Spence, M. 1973. Job market signaling. The Quarterly Journal of Economics, 87(3): 355-374.

Wang, S. (2018). Microeconomic theory. 4th ed., Springer.

Wong, C. S., \& Law, K. S. 1999. Managing localization of human resources in the PRC: A practical model. Journal of World Business, 34(1): 26-40.

Wong, C. S., \& Law, K. S. 2002. The effects of leader and follower emotional intelligence on performance and attitude: An exploratory study. The Leadership Quarterly, 13: 243-274.

Yu, J., Lee, S.H., \& Han, K. 2015. FDI motives, market governance, and ownership choice of MNEs: A study of Malaysia and Thailand from an incomplete contracting perspective. Asia Pacific Journal of Management, 32(2): 335-362.

Publisher's note Springer Nature remains neutral with regard to jurisdictional claims in published maps and institutional affiliations. 